\title{
The Language Question in the Teaching and Examination of 'A' Level Shona: A Case of Masvingo District in Zimbabwe
}

\author{
Viriri Eunitah \\ Great Zimbabwe University, Zimbabwe \\ Rubaya Clemence \\ Great Zimbabwe University, Zimbabwe
}

\begin{abstract}
This paper investigates the perceptions of Zimbabwean teachers, examiners and pupils towards the shift from English to Shona in the teaching and examination of Advanced level ('A' level) Shona Paper 2 in a context where English, a foreign language, has always mediated the teaching and examining of this paper. The paper also attempts to discover the attendant impact that this linguistic shift has had on candidates' performance in the examinations. Research findings indicate that although the official policy advocates using Shona language to teach Shona, practice in some schools indicates a laissez-faire implementation of the policy where individual teachers continued to rely on English or, in some cases, code-switched from Shona to English during classroom interactions. Most teachers castigated the existing situation where there were more Shona Grammar textbooks written in English compared to Shona, a situation that demanded translation competence from teachers whose own college and university training had been done in English. However, the introduction of Shona in the teaching of ' $A$ ' level Shona Paper 2 has been widely welcomed as a development which has helped Zimbabwe retain her linguistic autonomy. The majority of respondents argued that it is intellectually cramping for learners to be expected to 'learn' their own language in a 'borrowed' language as this negates their performance in the national examinations. The paradox of this research, however, is that although the introduction of Shona has engendered a marked quantitative increase in the number of candidates passing ZIMSEC examinations, the quality of examination passes has been affected.
\end{abstract}

Index Terms - competence, quality, endoglossic/exoglossic language policy, medium of instruction

\section{BACKGROUND}

The question about which language(s) to use in education has been the subject of debate for long, drawing the attention of many language experts in Africa. Most African countries have preferred to use foreign languages as media of instruction and so mother tongue instruction has been largely sidelined. This has resulted in the compromisation of meaningful learning resulting in underachievement in public examinations. In most Southern African countries, language policies in Education are a direct consequence of our colonial history. In the Zimbabwean context, schools inherited a colonial education system where English was imposed as the language of instruction in the teaching-learning process. Such an exoglossic language policy meant that all subjects in the school curriculum, including the indigenous languages Shona and Ndebele, were taught through the medium of a foreign language, English, for reasons outlined below:

- Education in Zimbabwe was closely modeled on the British pattern both in content and organization and so teaching the content in indigenous languages would pose problems (Chikomba, 1988)

- Examinations came from various British examining boards such as London General Certificate of Education and the Cambridge Certificate. According to Jolly (1969), public examinations taken in secondary schools were versions (often unchanged) of those current in Britain and so there was broad agreement between missionaries who were initially responsible for the schools and colonial governments to use the second language as the medium of instruction.

- English, as the language of the dominant power was the vehicle for colonial elitedom (Ngugi, 1987)

- English together with a highly selective examination system, ensured that education was limited to a small minority (Ngara, 1982)

- It was also for the obstruction or the deliberate undervaluing of a people's culture (Ngugi, 1987)

- The absence of a strong political will among leaders to genuinely promote and develop indigenous languages to appreciable levels of modernity.

For these and other reasons, indigenous languages were relegated to the fringes and confined to the informal sector in what has been perceived as "the relatively unimportant family, social and cultural domains" (Chimhundu, 1993, p. 41). This saw English becoming the language of the school, government, administration, commerce etc. creating a situation where the language at school became strange to the learners. 
However, the continued use of English in post independent Zimbabwe at the expense of indigenous languages has been an issue embroiled in much controversy among language experts, parents, teachers and school pupils themselves with some frowning upon the prospect of adopting an endoglossic language policy where indigenous languages are the media of instruction.

Since independence in 1980, gradual effort has been made to get Zimbabweans accept that mother tongue can be effectively employed for educational purposes. For instance, through the Education Act of 1987(as amended in 1990) in Section 55 of Part XI which is headed "Languages to be taught in schools", Shona and Ndebele which are national languages were introduced for the first time as media of instruction only up to grade 3. The Education Act of 1987 states that "Prior to the fourth grade, either Shona or Ndebele may be used as the medium of instruction. From the Fourth grade, English shall be the medium of instruction provided that Shona or Ndebele shall be taught as subjects..." (Nziramasanga, 1999, p. 156). Limiting the introduction of indigenous languages up to grade 3 and the use of the word 'may' reflect half-hearted attempts by the reality definers of the day to fully indigenise the curriculum. It meant that the prerogative to use indigenous languages remained a preserve of the teacher. Even when Shona and Ndebele were taught as subjects, they were taught and examined in English. As an example, fifteen years after independence, the 1995 'A' level Shona Paper 2 still has instructions and questions given in both English and Shona and students were expected to answer the Grammar section of this paper entirely in English. All this is indicative of how difficult it has been to accept the use of indigenous languages in the classroom as if to imply that African languages lack the technical and scientific terms needed to understand today's complex world (Obanya, 1992).

The Education Act was only revised in 2006 where mother tongue instruction was extended up to Grade 7 . This means that despite gaining her political independence a long way back, Zimbabwe's language policy has remained largely exoglossic where a foreign language has continued to dominate the linguistic landscape of the country.

However, this limited introduction of indigenous languages in the teaching-learning process has resulted in a chorus of voices decrying the use of indigenous languages that were perceived as less developed for use in the classroom (Obanya, 1992). In some sectors, such sentiments have been viewed as colonial mentality with arguments being proffered to refute claims of indigenous languages being handicapped to incorporate knowledge. For instance, African languages have proved that this is possible as they have done over the years through coinages and adaptations (Kottey, 1977). Moreover, "these languages which are world languages of communication today were once considered 'languages of the barbarians', unfit for the communication of knowledge at the time when Greek and Latin were the languages of civilization par excellence" (Mkandawire, 2005, p.176) and the argument is this can also happen to African languages.

\section{A Brief History of Shona Teaching In ZimbabWE}

The Zimbabwean linguistic landscape shows that there are 16 indigenous languages spoken in the country which include Shona, Ndebele, Tonga, Venda, Shangaan, Nambya, and Kalanga. Shona is by far the most spoken language by at least $75 \%$ of the Zimbabwean population followed by Ndebele which is spoken by up to $16.5 \%$ (Hachipola, 1996). In contrast, the percentage of the population for whom English is the mother tongue is quite small, about 3.5\%. Despite this distribution, it is English, a minority language, that has become the official language of instruction elbowing Shona and Ndebele which are spoken by about $91.5 \%$ when put together. Because of their wide demographic and geographic distribution, Doke in 1931 recommended that Shona and Ndebele gain the status of major languages of Zimbabwe and consequently, these have been taught as subjects up to university level. Unfortunately, the teaching and examining of some components of these major languages has been mediated through another language, English, a situation that Jalling (1969) calls "teaching about the language as opposed to teaching the language itself" (p. 44).

Doke's works on the unification of the Shona dialects formed a basis for the development of literature in Shona and in 1957 Shona was introduced as an examinable subject at 'O'level where Paper 2 (Grammar section) was taught and examined in English. At 'A' level, Shona as a subject was introduced in 1977 and divided into three examinable papers, namely Paper 1, Paper 2 and Paper 3. Paper 1 which comprises Rondedzero (Composition), Nzwisiso (Comprehension) and Pfupiso (Summary) has always been taught and examined in Shona even from colonial times. On the other hand, Paper 3 on Uvaranomwe (Literature) was taught and examined through the media of both English and Shona where the prerogative was left on the teacher to choose on the language for his own group of pupils though most chose English. This Paper became purely Shona mediated as early as 1983 and this meant that only Paper 2 with Mhenenguro (Practical Criticism) and Dudziramutauro (Grammar) continued to be taught and examined in English until as late as 2006 when curriculum planners, amid public outcry and resistance, resolved that this Paper too be taught and examined only in Shona. The interest of the researchers of this current investigation has been drawn by the questions which have continued to be asked on the wisdom of this 2006 decision to depart from teaching and examining Shona in English as some people seem to suggest that we revert to the colonial set up. It is against this background that the researchers decided to investigate the different attitudes of teachers and pupils towards the introduction of Shona as the only medium of instruction in 'A' level teaching of Shona Paper 2 that has been subject of so much debate given that Paper 3 of the same subject switched to Shona 3 years after independence, yet, it took this Paper 26 years after independence before it began to be taught and examined in Shona. What one can draw from this is that policy makers are still undecided on whether to adopt an endoglossic or exoglossic language policy. 


\section{METHODOLOGY}

In carrying out this study the research design adopted was mainly qualitative and data was collected through observation, questionnaires and interviews involving twenty teachers and fifty pupils from purposively sampled rural, urban, boarding, day, mission and government secondary schools in Masvingo district. The population comprised twenty-four secondary schools with 'A' levels in the district. Ten schools representing all school types in the district were randomly selected. All 'A' level Shona teachers from the selected high schools and five randomly selected 'A' level Shona pupils from each school formed the sample. Their involvement was meant to get views from the key participants in the teaching -learning process. The researchers hoped that these two groups of participants who interfaced with the 'A' level Shona teaching-learning process on a daily basis had different perceptions concerning the use of Shona as the only medium of instruction in the teaching of Shona paper 2 which used to be taught and examined through English from 1975 up to 2006.

Questionnaires were distributed to the thirty teachers and eighty students. The questions mainly focused on their attitudes towards Shona as a language and as a subject as well as any perceived challenges of using Shona as a medium of instruction in teaching 'A' level Shona Paper 2. The questionnaires allowed respondents to express their views, perceptions and beliefs freely. The response rate was $100 \%$.

Two interview schedules were also drafted, one for teachers and the other one for pupils. Interviews were held with both teachers and pupils to verify data collected through questionnaires. Interview questions could be explained and rephrased whenever respondents failed to understand.

\section{FINDINGS}

Generally the research yielded mixed feelings towards the use of Shona as a medium of instruction in the teaching of Shona at 'A' level. Critical analysis of the findings reveals that 24 teachers (80\%) and 69 pupils $(86 \%)$ have accepted the move towards the use of Shona as directed by the Ministry against 6 teachers $(20 \%)$ and 11 pupils (14\%) who seemed to favour English-mediated Shona lessons.

There are several reasons why the majority of teachers and pupils alike welcome the teaching of Shona through Shona as opposed to using English. One major reason was that both teachers and pupils argued that they were more proficient in Shona than in English, a foreign language. Teachers and pupils showed that using Shona ensured that real and meaningful interaction and communication marked all Shona lessons as opposed to using an alien tongue which was likely to breed ineffective teaching techniques such as chorus teaching, rote learning, memorization and recall. The above findings buttress Moyana (1989)'s argument that education can only harness pupils' full potential when done in the learner's language.

Apart from that, most teachers indicated that though the ' $A$ ' level Shona pass-rate has been significantly rising since the introduction of Shona as the language of instruction in 2006, in essence, the quality of the passes has gone down. This was evidenced by 'A' level results for different years at three schools spanning from a period when English was used as the medium of instruction and when Shona replaced it.

TABLE 1:

'A' LEVEL SHONA RESULTS FOR 4 YEARS

\begin{tabular}{|c|c|c|c|c|c|c|c|c|c|c|}
\hline School & Year & $\begin{array}{l}\text { Total Number of } \\
\text { Shona Candidates }\end{array}$ & $\begin{array}{l}\text { A } \\
\text { Grade }\end{array}$ & $\begin{array}{l}\text { B } \\
\text { Grade }\end{array}$ & $\begin{array}{l}\text { C } \\
\text { Grade }\end{array}$ & $\begin{array}{l}\text { D } \\
\text { Grade }\end{array}$ & $\begin{array}{l}\mathbf{E} \\
\text { Grade }\end{array}$ & $\begin{array}{l}\text { O } \\
\text { Grade }\end{array}$ & F Grade & $\begin{array}{l}\% \text { Pass } \\
\text { rateTE }\end{array}$ \\
\hline \multirow[t]{4}{*}{$\mathbf{X}$} & 2002 & 45 & 1 & 5 & 5 & 11 & 9 & 10 & 4 & $68.9 \%$ \\
\hline & 2004 & 42 & 1 & 7 & 9 & 8 & 6 & 8 & 3 & $73.8 \%$ \\
\hline & 2006 & 37 & - & 6 & 17 & 6 & 7 & 1 & - & $97.3 \%$ \\
\hline & 2010 & 33 & - & 2 & 15 & 10 & 6 & - & - & $100 . \%$ \\
\hline \multirow[t]{4}{*}{$\mathbf{Y}$} & 2002 & 30 & - & 1 & 3 & 8 & 8 & 6 & 4 & $66.7 \%$ \\
\hline & 2004 & 44 & 1 & 3 & 12 & 11 & 10 & 5 & 2 & $84.1 \%$ \\
\hline & 2006 & 36 & 1 & 2 & 10 & 12 & 9 & 2 & - & $94.4 \%$ \\
\hline & 2010 & 22 & - & 5 & 3 & 7 & 6 & 1 & - & $95.5 \%$ \\
\hline \multirow[t]{4}{*}{$\mathbf{Z}$} & 2002 & 25 & - & 2 & 2 & 7 & 4 & 8 & 2 & $60.0 \%$ \\
\hline & 2004 & 30 & - & 1 & 12 & 9 & 3 & 4 & 1 & $83.3 \%$ \\
\hline & 2006 & 28 & - & 1 & 11 & 10 & 5 & 1 & - & $96.4 \%$ \\
\hline & 2010 & 32 & 1 & 2 & 13 & 14 & - & 2 & - & $93.8 \%$ \\
\hline
\end{tabular}

What the results confirm is that the Shona pass rate has generally increased since Shona replaced English as the medium of instruction in teaching Shona. However, in some instances, the quality of passes has generally gone down. It is the quantitative imperatives of this pass rate that teachers argue reflect how the use of Shona can benefit a large number of candidates.

Though there could be other reasons to explain the above marked improvement in the Shona 'A' level pass rate, at face value, it would appear that generally the introduction of Shona has injected impetus in pupil's performance as reflected by the pass rate. An interviewed teacher who also happened to be an examiner of this paper indicated that in 
the external examinations, pupils could now elaborate their answers clearly with minimal grammatical errors. Teachers attributed this to the fact that pupils could now conceptualise abstract ideas and express themselves clearly in their own mother language. The teachers stressed that a great injustice had been committed against the pupils all along by depriving them of their language implying that pupils who had shown potential in their Shona classes in years gone by but had failed their Shona examinations could easily have passed had Shona been introduced a little earlier. Pupils augmented the teachers' views by arguing that the Grammar and Practical Criticism components which hitherto had proved the most difficult and daunting areas had overnight become easier since they were now taught and examined through a familiar language. Pupils indicated that they could now easily engage in group discussions with less consultations of their teachers because their homes and rural backgrounds were sites and rich sources of the language.

Both teachers and pupils viewed teaching and learning Shona through their own language as an indispensable springboard towards reclaiming their lost cultural identity and independence since languages serve as means of transmitting and preserving cultural values. In teachers' views, instruction in the mother- tongue contributes in significant ways to the cultural affection of the child more than instruction in a foreign language. Thus, they claimed that the earlier policy of teaching Shona in English had estranged pupils to their cultural heritage, creating cultural hybrids that were half-baked in either English or Shona culture, an indication that it is difficult to take away a child's first language without adverse consequences. To many teachers and pupils, the use of Shona as the only medium of instruction in the paper had restored their pride in the mother tongue.

The teachers together with their pupils indicated that they were excited by the introduction of Shona as the only medium of instruction in Shona. This was marked by high participation of pupils during the Shona lessons. More to that, examples during lessons were easily drawn and given in context from the language and culture which they all knew. Using a language they understood best actually motivated pupils in the subject because they were comfortable with it unlike in the other subjects where English is the official medium. One pupil summed it up when he said, "Chirungu chinogozha and ukachivhuna vamwe vanokuseka zvokuti unozotya kutaura muclass" [Expressing oneself in English is difficult and if you communicate in broken English, colleagues will laugh at you making you ill prepared to contribute in class in future.] Thus, their argument was that Shona-mediated lessons were quite lively and interesting.

However, some teachers and pupils despised the use of Shona as a medium of instruction in Shona teaching supporting the use of English. A number of reasons were cited in support of their opinions.

One major reason why teachers frowned upon the use of Shona as a medium of instruction in the teaching of Shona was premised on the argument that they were used to teaching Shona grammar in English. Evidence also showed that most of these teachers had trained in Shona at the various colleges and universities where the subject was taught in English and so in their first years of using Shona to teach Shona, they lacked the appropriate Shona vocabulary, thereby creating a lot of confusion due to code-switching. Because the new terminology used in Grammar was not in their day to day vocabulary, they were forced to memorise the terms. Teachers indicated that it was not an easy task for them as adults to master the new terms as quickly as was expected and as a result they were discouraged by the tiresome exercise.

Apart from that, teachers (56\%) complained that their lack of competence in using Shona has been worsened by the fact that there are few textbooks written in Shona to enrich the teaching -learning process. They pointed out that the most available Shona textbooks were actually written in English. They also complained that it was not only textbooks that were written in English but the language of the syllabus and the examination reports was not very helpful as it remained foreign to teachers and pupils' classroom practice. The teachers gave a catalogue of the widely used 'A' level Shona Paper 2 textbooks and the linguistic medium used to write them as given below:

TABLE 2:

'A' LEVEL GRAMMAR TEXTBOOKS AND THE LINGUISTIC MEDIUM USED.

\begin{tabular}{|l|l|l|}
\hline Title & Author & Language used \\
\hline Dudziramutauro & Warinda, C and Mashiri, P & Shona \\
\hline Jekesa Pfungwa 3 & Chakamba, & English \\
\hline Focus Study Aids & Chigidi, W & English \\
\hline Grammatical Constructions vol 1 & Fortune, G & English \\
\hline Grammatical Constructions vol 2 & Fortune, G & English \\
\hline Ziva Mutauro & Mutokonyi, F.R & Shona \\
\hline
\end{tabular}

Cursory analysis of the above texts reveals that a crisis has been created by the dearth of material written in Shona as most texts are written in a language alien to the pupil's learning. What is interesting is that the majority of these texts, though written in English, have actually been written by Shona- speaking scholars. The implication drawn from all this is that the burden of translating the material into Shona lies heavy on the teachers' shoulders, some of whom might lack the requisite experience and knowledge to do so. In other words, the campaign to indigenize the 'A' level Shona Paper 2 has struck a wrong cord because there seems to be a disjunction between what policy makers advocate for and the reality on the book shelves. The attendant consequence of this scenario is that some teachers have no confidence when teaching this paper because they face challenges when translating English ideas into Shona.

The teachers further indicated that the challenge of using Shona as a medium in teaching Shona Paper 2 stemmed from the fact that they were not sure of the Shona terms which had been agreed upon in the 2006 Shona harmonization 
workshop held in Mutare by the Curriculum Development Unit (CDU) because the document had not been circulated to schools but only benefited those who attended the workshop. They argued that the problem with this development was that the grammar textbooks used in schools invariably used different Shona terms for the same linguistic term thereby creating challenges for teachers and pupils. As an example, the table below contrasts the terms used in two widely used 'A' level texts:

TABLE 3:

SHONA GRAMMAR TERMS USED IN DIFFERENT SHONA TEXTBOOKS

\begin{tabular}{|l|l|l|}
\hline Text:1 Zivamutauro & Text:2 Dudziramutauro & English Equivalent \\
\hline Chivakazwi & Chivakazwi & Morpheme \\
\hline susukidza & Chitsigisi & Stabiliser \\
\hline Chiratidzabato & Chiratidzamupanda & class affix \\
\hline Mapato & Mipanda & Noun classes \\
\hline chivakamberi & Dzitsi & Stem \\
\hline tambanudzachiito & Rebeso & Extension \\
\hline taridzarambo & Chiranduri & Negative inflection \\
\hline chiitowando & Chiitogama & Auxiliary verb \\
\hline taridzamuridzi & Chirevamwene & Possessive \\
\hline
\end{tabular}

The above table concedes that Shona, as a language, does not lack the technical vocabulary to describe concepts and this contradicts Phillipson's (1992) argument that African languages should not be used as media of instruction because they are not endowed with "highly developed technical and scientific terminology"(p.278) However, teachers have expressed that the Shona texts that are on the bookshelves have been published independent of each other. They complained that this lack of co-ordination in efforts to indigenize the Shona grammar textbooks has created discord in the terminology used in various schools thereby creating a situation where teachers and students alike get confused by the constant flux of terminology depending on the text they are currently using and this poses problems for a new teacher. For instance, if the English term 'class affix' is known in one text as 'chiratidzabato' and in another as 'chiratidzamupanda', such disharmony can only disorient and confuse teachers and pupils during lessons. Pupils compounded this argument when they expressed how confusing it was when they revised Shona past examination papers with pupils from other schools or those who have used different textbooks where pupils would argue over the appropriate terminology to use.

To add to the above problem, a document in which the agreed linguistic terms were published after the 2006 Mutare Workshop by the invited specialists which could have become handy has not been made available to all schools. Teachers have, thus, been made to rely on the above textbooks like Dudziramutauro, Ziva Mutauro and Jekesa Pfungwa which, as seen in the table above, use different terminology to describe similar concepts. It will appear, however, that one factor that continues to militate against quality performance by pupils in the Shona Paper 2 examinations issues from use of inappropriate terminology. For instance, a comment from the Zimbabwe School Examinations Council (ZIMSEC) 2007 Shona Report on reasons why pupils had performed poorly in the 2007 examinations indicates that candidates "lacked the appropriate terminology or they produced incoherent and sometimes meaningless statements." What this demonstrates is that as long as the grammatical terms which have been agreed upon are not circulated to all schools, differences in terminology will always haunt Shona teachers and the quality of pupils' grades will continue to hog the light.

Suggestions from $22 \%$ of the respondents have been that the grammar content should continue to be taught in English or that schools continue to be given an option to choose a language of their choice. They based their argument on what one teacher summed up as "unusually long unShona terms" found in the Shona textbooks which were not used in day to day life. Teachers quoted terms such as 'ndevobonga' [clause], 'ndevobongasimboti' [main clause], 'chiratidzanguva chenguva ichauya' [future tense sign], nzvovera [vowel], nzvanyira [consonant] etc. which they described as frightening and absent in their everyday communication. Some teachers (27\%) also indicated that Shona had actually become more difficult than before and this had seen the number of pupils doing Shona at A level plummeting in their schools when compared to the period when English was used. They attributed this development to the introduction of difficult new Shona terms which were a mouthful for both teacher and pupil.

During lesson observations, the researchers discovered that lessons were very lively and marked by high pupil participation. Some of the observations which were made by the researchers are summed up below:

- A lot of code-switching from Shona to English was noticed during the teaching- learning process. Teachers borrowed words from English, the former medium and the researchers felt that this has a debilitating effect on pupils' performance since end of year examinations are examined and written in Shona.

- There were limited resources written in Shona and forced teachers to resort to grammar textbooks written in English which will end up confusing pupils since they will be required to translate the English notes into Shona.

- There is a general lack of interest in learning through Shona in some schools because some feel that best education can only be delivered through English.

- Most high school teachers have been trained in English at Universities and Colleges and therefore are not very comfortable to teach in Shona. 
- The Shona syllabus is still in English and this poses difficulties in translation.

- Shona examination reports which are sent to schools are written in English.

- Pupils resorted to memorizing Shona grammatical terms pointing out that the terms did not exist in everyday language.

\section{DISCUSSION}

The major purpose of this study was to investigate the attitudes of teachers and pupils towards the use of Shona as a medium of instruction in the teaching and examination of ' $A$ ' level Shona Paper 2 which unexplainably is the only Shona paper that continued to be taught in English, 26 years after Zimbabwe gained independence. Although independence had ushered in a new language policy dispensation where Shona replaced English as the medium of instruction in teaching Shona, only this Paper in question had defied this change. The researchers of this paper, therefore, set out to investigate whether teachers and pupils perceived Shona as inherently inferior to English or not, the impact that the switch to Shona from English had engendered as well as any challenges this switch posed.

The study has shown that the introduction of Shona as the medium of instruction was accepted by the majority as essential. One reason was that, the continued subordination of Shona to English in a post-colonial epoch is viewed wielding the potent to push this indigenous language into extinction and stagnation as well as lead to cultural deracination where the Shona cultural heritage crumbles as pupils end up imbibing and internalizing the English norms. The paper established that Shona, as the mother tongue, helps harness pupils' full potential in the subject as they are more proficient in Shona than in English.

Evidence has also proved that Shona is as rich as any other language, capable of coping with its immediate realities and can expand its linguistic repertoire to cope with new experiences. This is reflected by the publication of a number of Shona textbooks with wide technical vocabulary to describe terms hitherto understood only in English. However, the study showed that there is lack of co-ordination in efforts to develop the technical vocabulary for use by schools as writers of textbooks coin the new terms independent of each other. This has created discord in the way Shona terms are construed and understood by teachers and pupils who use different textbooks, a situation which teachers argued might result in pupils' passes being of low quality.

\section{RECOMMENDATIONS}

Basing on the findings of this study, the researchers hail the use of Shona as important but recommend that:

- if Shona is to be used as a medium effectively, teachers should be well grounded in it and the use of Shona as medium of teaching Shona should be extended up to college and university level as a preparatory phase for effective instruction later after graduation.

- the 'A' level Shona textbooks, syllabus and examination reports should not be written in English but in very clear Shona so that both teachers and pupils can interpret them without any difficulties and improve on areas of concern.

- the new dictionary on linguistic terminology and literature entitled Duramazwi reUvaranomwe neDudziramutauro which has been published should be made easily available to the teachers and pupils.

- teachers who trained through the medium of English need staff development especially from the examiners so that they can be sure of what is needed in the Paper.

\section{REFERENCES}

[1] Bambgose, A. (1991). Language and the Nation: The Language Question in Sub-Saharan Africa. Edinburgh: Edinburgh University Press.

[2] Chikomba, C.et al. (1988). Education in the New Zimbabwe. Michigan: Michigan State University.

[3] Chimhundu, H. (1993). "The Vernacularisation of African Languages after Independence" In Diogenes, 10. 161, pp35-42.

[4] Fafunwa, A.B. (1990). Using African languages in Education: A Challenge to Educators. In UNESCO-UNICEF, African Thoughts on the Prospects of Education for all .Unesco Breda (1990), 97-110.

[5] Hachipola, J.S. (1996). Survey of the Minority Languages of Zimbabwe: A Research Report (unpublished). University of Zimbabwe: Department of African Languages and Literature.

[6] Jolly, R. (ed). (1969). Education in Africa: Research and Action. Nairobi: East African Publishing House.

[7] Kotey, P.A. (1977). Language and Linguistic Problems in Africa: Proceedings of the VII Conferences on African Linguists. Oxford: Oxford University.

[8] Magwa, W. (2006). Mother Tongue Medium Education in Zimbabwe: New Perspectives and Challenges. Midlands State University: Department of African Languages and Culture.

[9] Mkandawire, T. (2005). African Intellectuals Rethinking Politics, Language, Gender and Development. New York: Zed Books.

[10] Moyana, T.T. (1989). Education, Liberation and the Creative Art. Harare: Zimbabwe Publishing House.

[11] Ngara, E.A. (1982). Bilingualism, Language Contact and Planning. Gweru: Mambo Press.

[12] Ngugi Wa Thiongo. (1987). Decolonizing the Mind: The Politics in African Literature. Harare: Zimbabwe Publishing House.

[13] Nziramasanga, C.T. (1999). Report of the Presidential Commission of Inquiry into Education and Training. Harare: Government printers. 
[14] Obanya, P. (1992). Language Issues in Basic Education and Literacy. Conference Paper. UNESCO Institute of Education: Hamburg.

[15] Phillipson, R. (1992). Linguistic Imperialism. Oxford: Oxford University Press.

[16] Prah, K.K. (ed). (2000). Between Distinction and Education: The Harmonization and Standardization of African Languages. Cape Town: Centre for Advanced Studies of African Society.

[17] Unesco Report. (1985). African Community Languages and Their Use in Literacy and Education: A Regional Survey. Dakar: Unesco.

Viriri Eunitah was born on 04 April 1978 in Buhera District, Zimbabwe. E. Viriri is a holder of a Master of Education Degree (2007), a Post Graduate Diploma in Education (2004) and a Bachelor of Arts General Degree (2000) from the University of Zimbabwe in Harare, Zimbabwe.

She has worked as a secondary school TEACHER for ten years (end 2000 - 2010). Currently she is a LECTURER at Great Zimbabwe University. She is interested in researching on language and educational issues.

Rubaya Clemence who was born on 29 September 1971 holds of a Master of Education degree in English (2007), a Bachelor of Education degree in English (2002) from the University of Zimbabwe. Having worked as a high school TEACHER for twelve years, he is currently a Communication Studies LECTURER at Great Zimbabwe University. His research interests lie in literature, communication and curriculum issues. 